\title{
Diet Quality, Child Health, and Food Policies in Developing Countries
}

Alok Bhargava

Although the importance of diet quality for improving child health is widely recognized, the roles of environmental factors and the absorption of nutrients for children's physical growth and morbidity have not been adequately integrated into a policy framework. Moreover, nutrient intakes gradually affect child health, so it is helpful to use alternative tools to evaluate short-term interventions versus long-term food policies. This article emphasizes the role of diet quality reflected in the intake of nutrients such as protein, calcium, and iron for children's physical growth. Vitamins $A$ and $C$ are important for reducing morbidity. Children's growth and morbidity affect their cognitive development, which is critical for the future supply of skilled labor and economic growth. Evidence on these issues from countries such as Bangladesh, India, Kenya, the Philippines, and Tanzania is summarized. The supply of nutritious foods is appraised from the viewpoint of improving diet quality. Finally, the roles of educational campaigns and indirect taxes on unhealthy processed foods consumed by the affluent in developing countries are discussed. Economic development, food policies, diet quality, child health, morbidity, cognitive development, livestock production, educational campaigns, indirect taxation. JEL codes: O12, I15, I25, J10, Q01, Q18

Analyzing the effects of food intake on health outcomes is a complex topic, partly because of the role of socioeconomic and behavioral factors and because of interdependence in the absorption of nutrients by the human body. Such issues require multi-disciplinary approaches, as recognized in the biomedical and social sciences. Stigler (1945), for example, noted that because "the optimum quantity of any nutrient depends upon the quantities of other nutrients available", the "ultimate health function will doubtless be very complex". The efficacy of food polices is likely to 
depend on nutritional knowledge incorporated into the design. For example, approximately 3 billion individuals in developing countries suffer from iron deficiencies (UNICEF/UNU/WHO/MI 1999). Iron intake from animal sources ("heme") is low, whereas non-heme iron from grains is poorly absorbed due to the presence of phytates. It is essential to exploit interactions between nutrients such as vitamins A and $\mathrm{C}$, which enhance non-heme iron absorption, to devise cost-effective food policies (Bhargava, Bouis, and Scrimshaw 2001).

There are at least four sets of issues that need to be addressed in developing food policy frameworks for analyzing the effects of diet quality on child health. First, although short-term interventions that provide nutritional supplements to children in the settings of randomized controlled trials are common in biomedical sciences, it is essential that such studies facilitate policy making over a longer time frame. Households' food intakes are influenced by cultural, geographical, socioeconomic, and demographic factors. Thus, the formulation of long-term food policies entails integration of the evidence from short-term studies into a broader framework that recognizes the circumstances that prevail in countries (Bhargava 2008).

Second, the role of environmental factors, such as poor sanitation and hygiene, for children's physical growth has not been adequately integrated into the policy literature. For example, children in developing countries are unlikely to achieve their full linear growth potential despite adequate food supplies because repeated episodes of diarrheal and other morbidities exacerbate nutrient loss. At the other extreme, height in the Netherlands has surpassed all countries since the Second World War, presumably due to the school milk programs that encouraged and rewarded children for drinking up to five glasses of milk daily by becoming "M-brigadiers" (Dutch School Milk Programs 2011). The programs were accompanied by improvements in public health infrastructure and were discontinued in the 1980s; a reversion to the mean in Dutch heights might be expected in the early $21^{\text {st }}$ century (Schonbeck et al. 2013, figure 2). Policy makers need to underscore the absorption of nutrients, which depends not only on food intake but also on infection (Scrimshaw and San Giovanni 1997). Evidence from India indicates that timely vaccination can prevent childhood morbidity and enhance physical growth (Bhargava, Guntupalli, and Lokshin 2011; Bhargava et al. 2014).

Third, diet quality, reflected in the intake of protein and iron, is critical for children's brain development (Monckeberg 1975). Evidence from developing countries indicates the importance of adequate energy and nutrient intakes for learning (Pollitt et al. 1993) and for physical and mental development, which are intertwined (Bhargava 2008). Moreover, in a globalized economy, children's cognitive development is critical for the skilled labor force that determines productivity. For example, countries such as Japan, South Korea, and China have been successful in increasing economic growth by investing in children's education. School infrastructure is important for learning, and school meal programs (Alderman and Bundy 2012) 
can help improve diet quality. Although diet quality and school infrastructure are likely to have synergistic effects on cognitive development, cost-benefit analyses may be necessary for an equitable resource allocation in countries where a high proportion of children do not enroll in primary education and thus do not benefit from school programs.

The final set of issues is the availability of nutritious foods at affordable prices for poor households. In countries where stunting is prevalent due to low calcium intakes, for example, higher productivity in dairy farming and efficiency in food distribution systems can improve children's diet quality. The coordination of food production and distribution may be intricate because of conflicting interests (Pinstrup-Andersen 2013), but higher dairy production can increase the consumption of milk products and meats because these foods are appealing to poor households. In contrast, the introduction of new vegetables, such as orange flesh sweet potato containing higher quantities of $\beta$-carotene (Hotz et al. 2012), may need to be accompanied by nutrition education programs to increase awareness. Moreover, unhealthy food consumption, such as the consumption of processed foods high in fats and sugars by the affluent, should be discouraged via educational campaigns and indirect taxes because it imposes a negative externality; disproportionately higher medical resources are utilized for treating chronic diseases among the affluent (Bhargava 2001).

The structure of this paper is as follows. Next, the role of cultural, demographic and economic factors that affect diets is outlined, followed by a discussion of the fortification of foods and the sustainability of policies that enhance diet quality. Interventions in developing countries such as Guatemala, Colombia, India, the Philippines, and Uganda are also discussed in this section. Subsequently, methodological issues in the analyses of intake data from food expenditure surveys versus direct measurements are outlined, and the use of Food Frequency Questionnaires for assessing "diet diversity" is discussed (Arimond and Ruel 2004). Then, evidence is presented on children's energy and nutrient intakes using longitudinal data from India, the Philippines, and Kenya. The roles of environmental and nutritional factors that affect child morbidity are outlined, and studies showing the benefits of improvements in environmental conditions for child morbidity are discussed. Evidence on proximate determinants of child morbidity using longitudinal data from the Philippines, Kenya, and Bangladesh is then presented. Further, evidence is presented from a demographic survey in India on the effects of different foods consumed and their frequency on children and women's hemoglobin concentrations.

The importance of diet quality, morbidity, and school environment for children's cognitive development is next discussed. Evidence from Kenya and Tanzania is presented using longitudinal data. The role of livestock production and methods for improving the safety of dairy products are discussed, followed by a discussion concerning the role of educational campaigns for improving diet quality. Indirect taxes 
on unhealthy processed foods that are consumed by affluent populations in developing countries for raising additional revenues are discussed, and the policy implications of the evidence presented are summarized.

\section{The Determinants of Diet Quality and Food Policy Formulation}

Food consumption patterns of populations depend on cultural, socioeconomic, and demographic factors that are complex to simultaneously tackle in quantitative analyses. While biological factors such as energy and nutrient requirements influence food intakes, food prices and household incomes affect the intakes in developing countries. Even in developed countries, diet quality is affected by socioeconomic variables though individuals' nutritional knowledge is critical for selecting healthy diets.

\section{Socioeconomic and Cultural Factors and Diets in Developing Countries}

Historically, shortages of staple foods such as wheat and rice were widely prevalent leading to hunger and starvation (Dreze and Sen 1990; Fogel 1994). Thus, selling staple foods at subsidized prices has been a popular strategy for governments in developing countries for reducing under-nutrition. The early economics literature on food policies focused on stabilizing prices of staple foods that are a large proportion of households' budgets (Timmer, Falcon, and Pearson 1983). Recent increases in food production have reduced shortages in developing countries, though deficiencies of protein and micronutrients reflecting poor diet quality remain widely prevalent.

In traditional societies, food consumption depends on local crops so that climate is an important factor. For example, rice, wheat, maize, and cassava have emerged as staple foods over the centuries and the choice is influenced by production constraints. An important contribution of economists has been to recognize that behavioral factors affect diets. For example, Gorman (1967) noted that "choices depend on tastes and tastes depend on past choices". Implicit in this phenomenon of "habit persistence' is that changes in diets occur gradually. If, for example, the price of milk falls in a developing country, then poor parents may gradually increase children's milk intakes. From an econometric modeling standpoint, it is appealing to include previous levels of demand as explanatory variables in dynamic models; longitudinal data are necessary for estimating such models. Additionally, mineral and vitamin contents of foods are "characteristics" that can be incorporated in the models.

Though the effects of prices and incomes on food consumption may not be apparent in developed countries, demand for nutritious foods in developing countries is influenced by food prices and household incomes. Moreover, modeling the effects of food prices on consumption has typically relied on cross-sectional data covering 
several geographical regions. In contrast, longitudinal studies, including randomized controlled trials, are often restricted to specific regions for logistical reasons. Thus, analyses of data from longitudinal dietary surveys are useful for estimating the short- and long-run income elasticities of energy and nutrient intakes. The magnitudes of income elasticities are helpful for formulating food policies, particularly when the models incorporate the knowledge from biomedical sciences and nutritional interventions.

\section{Food Fortification, Nutritional Interventions, and Food Policies}

Various schemes have been devised for developing countries for fortification of foods with the deficient nutrients such as iodine, calcium, iron, and vitamins A and D (e.g., Bauernfeind 1994). Moreover, fortified gruels such as "Incaparina" in Guatemala, "Colombiharina" in Colombia, and "Bal-Ahar" in India have enabled increases in micronutrients intakes by children from poor households. Free or subsidized distribution of such foods via non-governmental organizations and/or schools especially in remote areas is likely to improve children's nutritional intakes above that afforded by household incomes. However, the bioavailability of nutrients such as calcium and iron is often low from fortified foods due to the presence of phytates than from dairy products that are regularly consumed by well-off households in developing countries.

While school milk programs in the Netherlands led to increases in heights within two decades, one would expect smaller gains from interventions such as in Guatemala (Martorell et al. 2005) providing the fortified gruel due to lower nutrient absorption rates. Similarly, interventions providing iron-dense rice to Filipino nuns showed small effects on ferritin concentrations that are indicators of iron stores (Haas et al. 2005). Moreover, while introduction of orange flesh sweet potato containing higher $\beta$-carotene in Uganda led to significantly higher intakes (Hotz et al. 2012), the effects on serum retinol levels were insignificant. These findings may have been partly due to inflammations in developing countries that complicate interpretation of data from randomized controlled trials (Bhargava et al. 2003b). From a policy viewpoint, it would be helpful to exploit modern technologies for increasing micronutrient content of grains and vegetables (e.g., Nestel et al. 2006; Ruel and Alderman 2013) and increase the supply of fortified foods and nutritious dairy products in developing countries.

From a methodological standpoint, primary studies in nutritional sciences often devise short-term interventions supplementing populations such as children, pregnant or lactating women, and adults with fortified foods or micronutrient in the form of tablets (e.g., Bhutta et al. 2013). Though assessing the efficacy of interventions via randomized controlled trials is appealing, the results should be useful for the formulation of long-term food policies. This is important because the outcomes 
of many short-term studies can be predicted from the knowledge in biomedical sciences or from previous studies. For example, it is known that pregnant women require higher intakes of absorbable iron; iron supplementation during pregnancy is likely to be beneficial for intrauterine growth and birth outcomes (Ekstrom et al. 2002). In contrast, a more expensive alternative would be to provide nutritious foods to poor women that women from well-off backgrounds consume during pregnancy. Though the former policies entails monitoring women for avoiding unintended consequences of iron supplementation such as increased malarial morbidity and/or poor tolerance, the latter is appealing from a food policy standpoint since it entails no risks.

In the above example, it may be intricate to compare the benefits for women's iron status of iron tablets versus improvements in diet quality. From a short-term cost-benefit viewpoint, the former might seem an effective strategy though the costs of medical monitoring need to be taken into account. In contrast, improvements in women's iron status achieved via diets have the potential for improving dietary behavior and future pregnancy outcomes. Thus, randomized controlled trials are useful for identifying appropriate interventions for population groups (Bhargava 2008). From a food and health policy standpoint, the important issue is the degree to which such findings can be integrated into long-term policies.

Another example involving food supplementation for children in a longer time frame is the Institute of Nutrition of Central America and Panama (INCAP) study in Guatemala (Martorell and Scrimshaw 1995). Pre-school children in the intervention group received a nutritious supplement ("Atole") high in protein during 1969-77. Children in the control group received a drink fortified with micronutrients ("Fresco"). Partly because children receiving Atole were taller in follow-up studies (Martorell et al. 2005), interventions providing fortified gruels such as "Incaparina" became popular. Additionally, the next generations of children in the age group 0-12 years born to daughters of Atole-supplemented mothers were taller and had higher head circumferences (Behrman et al. 2009). Moreover, supplemented children had higher scores on certain cognitive tests administered when they were adults (Maluccio et al. 2009). Though the analyses of these data might have controlled for various explanatory variables at different time points in a longitudinal fashion, it is likely that nutrient content of foods consumed and environmental factors played an important role in children's physical growth and cognitive development.

Overall, the evaluation of benefits of food policies for population health entails a longer time frame and requires more complex analyses than comparisons of changes in means in Control and Intervention groups. Additionally, measurement issues in nutrition research are important for assessing the magnitudes of effects of socioeconomic variables on dietary intakes and are discussed next. 
The energy and nutrient intakes data from developing countries in early economics research were primarily derived from food expenditure surveys (e.g., Timmer, Falcon, and Pearson 1983). Households' expenditures on food groups such as grains, meat, vegetables, and milk can be converted into energy and nutrients using food conversion tables. More recent research has measured food intakes via methods such as 24-hour recalls (Binswanger and Jodha 1978; Bouis and Haddad 1992; Bouis et al. 1998). Interviewers visit the households and ask members "what did you consume in the last 24 hours" and inquire about portion sizes. Food intakes can be converted into energy and nutrient intakes using a list of foods from several countries (Calloway, Murphy, and Bunch 1994).

From a food policy standpoint, it would be helpful to outline the relative merits of alternative methods for assessing intakes in developing countries. Data from household expenditure surveys are very aggregate and can provide insights since intrahousehold variation is reduced (e.g., Mahal and Karan 2008). However, the actual food intakes by individuals are difficult to assess; food consumed by "guests" and domestic help inflate the consumption (Bouis and Haddad 1992). Thus, without direct measurements on children's food intakes, it is difficult to assess the effects of diet quality on health outcomes. The 24-hour recall method affords detailed information on foods consumed by household members. Moreover, enumerators do not influence consumption behavior on the day of the visit as in the filling of "food records". However, the days on which 24-hour recall surveys are conducted may not be "typical" so that there may be high intra-individual variation in intakes. In the study in Kenya from which evidence will be presented below, the 24-hour recall method was augmented by measuring food intakes on the days of the visits (Neumann, Bwibo, and Sigman 1992).

Further, data on consumption of certain food groups by large number of women and children are compiled in demographic surveys in developing countries. This has led researchers such as Arimond and Ruel (2004) to explain child health outcomes using indices of "diet diversity", i.e., individuals consuming greater variety of foods in the previous few days might have better health outcomes. Such methods are based on Food Frequency Questionnaires used in epidemiological research (e.g., Willett 1998, chapter 5). Information on frequency of foods consumed over a month or longer periods can also be utilized (Stefanik and Trulson 1962). Moreover, the reported quantities of foods consumed have been incorporated to create "diet diversity scores" (Moursi et al. 2008). Such methods are referred to as "Semi-quantitative Food Frequency Questionnaires" (Block et al. 1986; Sempos 1992; Carroll, Freedman, and Hartman 1996) and are generally less informative than 24-hour recalls, where actual food intakes are assessed by the enumerators. 
Next, food frequency type methods are likely to require large sample sizes for investigating the effects of dietary intakes on health outcomes. In an analysis of the proximate determinants of children's stunting reflected in their height-for-age using data from demographic surveys in Bangladesh, Ethiopia, Haiti, India, Kenya, Uganda, Zambia, and Zimbabwe, Jones et al. (2014) reported a significant association of "minimum diet diversity" score only for India in their logistic models; this variable was significantly associated with height-for-age in regression models for Bangladesh, India, and Zambia. Though ante-natal care and socioeconomic variables were included in the models, post-natal care reflected in childhood immunizations was not accounted for. In fact, children's vaccinations against DPT, polio, and measles and anthelmintic treatment were significantly associated with heights in India using the National Family Health Survey-3 data (Bhargava, Guntupalli, and Lokshin 2011). The importance of large sample sizes when data from food frequency questionnaires are employed to explain the hemoglobin concentration of women and children in India is illustrated below.

Finally, it is useful to assess how diet quality changes with incomes, education, and nutritional knowledge in developing countries. Using individual food intakes data, one would expect income elasticities to be high for nutrients such as calcium, iron, and vitamins $\mathrm{A}$ and $\mathrm{C}$ that are regularly consumed by well-off households. Unless populations face chronic food shortages, one would expect income elasticity of energy intakes to be small in magnitude. This is because higher than necessary energy intakes by individuals engaged in light to moderate physical activity levels are likely to lead to weight gain. Another procedure for investigating diet quality in developing countries is by expressing the intakes of protein and micronutrients as ratios to total energy intake (Bhargava 1991a). Such ratios are useful because individuals' energy intakes are influenced by their energy expenditures that cannot be measured without laboratory methods.

\section{Income Elasticities of Energy and Nutrient Intakes for India, the Philippines, and Kenya}

The income elasticities of energy and nutrient intakes can be estimated more robustly using longitudinal data because the effects of intra-individual variation are minimized. Moreover, the models should include explanatory variables such as maternal education, household size and composition, and total expenditures or incomes. Unobserved heterogeneity in intakes can be addressed by including "random" or "fixed" effects in the models. Because longitudinal data are available from India, the Philippines, and Kenya on large numbers of individuals for few time periods, the use of random effects models is appealing for the efficient estimation of model parameters. Additionally, one can estimate dynamic models that reflect habit persistence in diets. Static models are useful when very few time observations are available. 
In previous research, Behrman and Deolalikar (1987) analyzed 24-hour recall data collected in four survey rounds in 1976-7 in south India by the International Crop Research Institute for Semi-arid Tropics (ICRISAT) (Binswanger and Jodha 1978). The intakes were aggregated for household members and were averaged over the four survey rounds; the model was estimated using Ordinary Least Squares. The main findings were that income elasticities of energy and nutrients such as protein, calcium, iron, and vitamins A and B (niacin, riboflavin, and thiamine) were not significantly different from zero. The authors concluded that individuals in rural India do not nourish themselves better despite increases in household incomes. However, these findings were due to model formulation and the choice of the estimation methods (Bhargava 1991a,b).

The income elasticities of energy and nutrient intakes in table 1 were estimated using similar models and data from India, the Philippines, and Kenya. Partly because of high intra-individual variation, the intake data from India were averaged over two survey rounds to create annual data for 1976 and 1977. Additionally, the long-run income elasticities were estimated by maximum likelihood in more complex dynamic random effects models that considered inter-dependence in energy and nutrient intakes (Bhargava 1991a). For the Bukidnon region of the Philippines, 24-hour recall data in four survey rounds separated by four-month intervals in 1984-5 were analyzed (Bouis and Haddad 1992). For the Embu region of Kenya, augmented 24-hour recall data from three survey rounds separated by

Table 1. Short- and Long-Run Income Elasticities of Energy and Nutrient Intakes Estimated using Random Effects Models and Data from India, the Philippines, and Kenya

\begin{tabular}{|c|c|c|c|c|c|c|}
\hline \multirow{2}{*}{$\begin{array}{l}\text { Country: } \\
\text { Intakes: }\end{array}$} & \multicolumn{2}{|c|}{ India $(\text { static model })^{1}$} & \multicolumn{2}{|c|}{$\begin{array}{l}\text { Philippines } \\
{\text { (dynamic model })^{2}}^{2}\end{array}$} & \multicolumn{2}{|c|}{ Kenya $(\text { dynamic model })^{3}$} \\
\hline & Short run & Long run ${ }^{4}$ & Short run & Long run & Short run & Long run \\
\hline Energy & 0.05 & 0.13 & 0.08 & 0.09 & 0.29 & 0.29 \\
\hline Protein & 0.06 & 0.18 & 0.13 & 0.15 & 0.39 & 0.39 \\
\hline Calcium & 0.10 & 0.13 & 0.23 & 0.26 & 0.42 & 0.42 \\
\hline Iron & 0.0 & 0.13 & 0.19 & 0.22 & 0.31 & 0.31 \\
\hline Vitamin A & 0.10 & 0.18 & 0.21 & 0.21 & 0.26 & 0.26 \\
\hline Vitamin B & 0.13 & 0.32 & 0.30 & 0.33 & 0.30 & 0.30 \\
\hline Vitamin C & 0.10 & 0.18 & 0.02 & 0.02 & 0.37 & 0.37 \\
\hline \multicolumn{7}{|l|}{ Notes: } \\
\hline \multicolumn{7}{|c|}{$\begin{array}{l}\text { 2Maximum likelihood estimates using data on } 312 \text { children in four periods (source: Bhargava 1994). } \\
{ }^{3} \text { MLE using data on } 100 \text { children in three periods (source: Bhargava and Fox-Kean 2003). }\end{array}$} \\
\hline
\end{tabular}


three-month intervals in 1984-5 were analyzed (Bhargava and Fox-Kean 2003). The socioeconomic status of Kenyan households was approximated by summing the number of household possessions and via a categorical variable (1-5) for cash income.

In table 1, the short-run income elasticities of energy intake for India and the Philippines were 0.05 and 0.08 , respectively. The long run elasticities were slightly higher. In contrast, the short- and long-run income elasticities of energy intake in Kenya were 0.29 and 0.34 , respectively. The differences in magnitudes were not surprising because the Embu region is poorer than south Indian villages and the Bukidnon region of the Philippines. Moreover, there was a drought in the Embu region during the study, which led to food shortages. Note that the income elasticity of energy intakes estimated using food expenditures data from Bangladesh was 0.80 (Pitt 1983); such estimates are likely to be due to the high degree of aggregation.

The income elasticities of protein, calcium, iron, and vitamins $\mathrm{A}, \mathrm{B}$, and $\mathrm{C}$ can shed light on the effects of increases in household incomes on the quality of diets in developing countries. Using the static model for India, the short-run income elasticity of protein was 0.06, which seems low. However, in the more complex dynamic model, the corresponding long-run estimate was 0.18. Because there were only two time observations for the Indian data, it will be useful to focus on elasticities estimated from static models. Income elasticities of calcium, vitamins A, B, and C were in the interval $[0.10,0.13]$. These were significantly larger than the income elasticity of energy intakes and reflected improvements in diet quality with increases in household incomes.

For the Philippines, nutrient intake data from four survey rounds showed lower intra-individual variation, in part because climatic variation is low due to proximity to the sea. Additionally, fresh and dried fish are available, facilitating higher intakes of protein and micronutrients. The long-run income elasticity of protein was 0.15 , and the long-run income elasticities of vitamins A and B were 0.21 and 0.30 , respectively. These elasticities indicate improvements in diet quality with increases in household incomes. However, the income elasticity of vitamin C intakes was not significantly different from zero, possibly because fresh fruit prices exhibit higher seasonal variation; vitamin $\mathrm{C}$ is concentrated in fruits and leafy vegetables.

The income elasticities of nutrient intakes in Kenya were larger in magnitudes. For example, the long-run income elasticities of protein, calcium, and iron were $0.39,0.42$, and 0.31 , respectively. These estimates reflect the importance of household incomes and economic growth for diet quality in the Embu region. This was also true for energy intakes, where the long-run income elasticity was 0.34 , which was higher than those for India (0.13) and the Philippines (0.29). Some implications of these findings are discussed below. 


\section{Environmental Factors, Food Intake, and Child Health}

Children in developing countries are often sick with diarrhea, respiratory infections, and other diseases. Although the inter-connections between children's nutritional status and infection are recognized in biomedical sciences, these issues merit greater attention in the formulation of food policies. For example, episodes of diarrhea reduce children's food intake and entail a loss of vital nutrients that can be replenished through a diet high in micronutrients. Because the income elasticities of micronutrients are generally small and the foods consumed are often contaminated, repeated infections manifest in the form of physical growth retardation. Immunization programs can help reduce morbidity and nutrient loss, and iron loss among children infected with intestinal parasites can be prevented via anthelmintic treatment. For long-term improvements in child growth, it is important to improve diet quality via food policies.

Further, poor sanitation is ubiquitous in many developing countries due to the high costs of sewage treatment (e.g., Bhargava et al. 2003a; Humphrey 2009; Spears 2013). Small-scale programs can improve water quality (Esrey et al. 1988). Demographic factors, such as high population density and a large number of children in households, can exacerbate the effects of environmental conditions (Arrow et al. 2012). Food policies are likely to have their intended effects if conditions facilitate the absorption of nutrients.

\section{Evidence on the Determinants of Child Morbidity in Developing Countries}

Gastrointestinal diseases, such as diarrhea, dysentery, cholera, and typhoid, are common in developing countries due to exposure to pathogens. Moreover, child morbidity often increases as young infants are weaned. In a study of 400 infants aged 4-8 months in the slums of New Delhi, 87 infants supplemented with a milk-based cereal experienced significantly greater episodes of fever and dysentery (Bhandari et al. 2001). Although the mothers were shown how to prepare the supplement and advised to wash their hands, the supplements were apparently contaminated in the preparation process. Additionally, at the time of the first supplementation, the children were younger than 6 months, which is the recommended age for weaning.

Further, interventions such as washing hands with soap have been found to reduce child morbidity. In a randomized controlled trial in Karachi, 25 neighborhoods were assigned to a program promoting hand washing using soap, and 11 neighborhoods served as controls (Luby et al. 2005). Approximately 300 households were in each group. The morbidity outcomes included the incidence of pneumonia, impetigo, and diarrhea. Children under five years of age in households that received soap had a 50 percent lower incidence of pneumonia than did the control group. Moreover, children under 15 years had a 53 percent lower incidence of 
diarrhea and a 34\% percent lower incidence of impetigo compared with the control group. All differences were statistically significant.

Episodes of diarrhea and other sicknesses can hamper children's physical growth. For example, a study by Checkley et al. (2003) found that among 225 Peruvian children followed from birth to 35 months, children who had diarrhea 10 percent of the time during the first 24 months were $1.5 \mathrm{~cm}$ shorter than their counterparts without diarrhea. Moreover, the adverse effects of diarrhea differed by age; diarrhea in the first 6 months appeared to result in long-term height deficits. However, food intakes were not measured in this study. It is plausible that the deficits in heights were not permanent and that food supplementation programs might have facilitated growth.

Overall, the formulation of food policies needs to incorporate environmental aspects, such as improvements in sanitation, to prevent nutrient loss. Moreover, it is often the case that well-nourished children have greater immunity to infections. If policy makers can improve child health in the early years, then these children may show greater resilience in the future.

\section{Evidence from Models of the Morbidity of Filipino, Kenyan, and Bangladeshi Children}

Although several studies have investigated the determinants of child morbidity in developing countries, few have modeled morbidity indices that capture the duration and intensity of sicknesses (Rand Corporation 1983; Bhargava 1994). This approach is important because children are often sick with multiple symptoms. For example, probit models for the likelihood of contracting diarrhea in the week preceding the survey partially reflect health status. Moreover, explanatory variables in these models should include intakes of micronutrients, such as vitamins A and C, which enhance immunity systems (Sommer 1986; Scrimshaw and San Giovanni 1997). In contrast, including children's energy intakes will not capture the benefits of nutritional status because sicknesses reduce energy intake (cf. Cebu Study Team 1991).

Further, it is important to investigate whether children's nutritional status as reflected in anthropometric measures such as height and weight and environmental variables such as access to sanitation and safe water are potential predictors of child morbidity. Biomarkers such as hemoglobin concentration are better indicators of iron status than intake because iron absorption rates are low. Although ferritin concentrations are indicators of body iron stores, they are elevated by inflammations and may not be reliable indicators in developing countries (Bhargava et al. 2003b). Moreover, empirical models should account for unobserved between-children differences and allow for the possible endogeneity of explanatory variables such as body weight, especially due to the presence of random effects (Bhargava, 1991b). 
The results from models explaining morbidity indices for children in the Philippines, Kenya, and Bangladesh by socioeconomic, dietary, and environmental variables are shown in table 2. The morbidity index for Filipino children was based on the duration of five symptoms (cold, cough, fever, diarrhea, and headache) in the previous fortnight. The morbidity index for Bangladeshi children was based on episodes of three of seven symptoms (diarrhea, dysentery, vomiting, stomachache, acidity, typhoid, and cholera) recorded for the previous month. The morbidity index for Kenyan children was quite detailed and covered more than 20 symptoms recorded on a weekly basis. The explanatory variables in Kenya and Bangladesh included children's hemoglobin concentration. The emphasis in the Bangladesh study was on the effects of water contamination; fecal and total coliforms in the water at the source and stored in the house were explanatory variables.

Table 2. Results from Estimating Random Effects Models for Child Morbidity Indices Explained by Household, Anthropometrics, Dietary Intakes, and Environmental Variables for the Philippines, Kenya, and Bangladesh

\begin{tabular}{|c|c|c|c|c|c|c|}
\hline \multirow{2}{*}{$\begin{array}{l}\text { Country: } \\
\text { Explanatory variables: }\end{array}$} & \multicolumn{2}{|l|}{ Philippines $^{1}$} & \multicolumn{2}{|l|}{ Kenya $^{2}$} & \multicolumn{2}{|c|}{ Bangladesh $^{3}$} \\
\hline & Coefficient & $\mathrm{SE}$ & Coefficient & SE & Coefficient & $\mathrm{SE}$ \\
\hline Constant & -16.56 & 3.88 & 21.55 & 0.18 & 38.69 & 0.31 \\
\hline Age (months) & $-0.53^{*}$ & 0.17 & - & & $-12.44^{*}$ & 0.16 \\
\hline Open pit toilet & $0.18^{*}$ & 0.09 & - & & - & \\
\hline Medical facility distance & $0.06^{*}$ & 0.02 & - & & - & \\
\hline Maternal housework & 0.05 & 0.04 & - & & - & \\
\hline Height (meters) & $4.37^{*}$ & 1.14 & - & & $-4.55^{*}$ & 1.00 \\
\hline Weight (Kg) & $-2.02^{*}$ & 0.47 & - & & $-2.35^{*}$ & 0.11 \\
\hline$\beta$-carotene (int. units) & $-0.04^{*}$ & 0.02 & - & & - & \\
\hline Hemoglobin (grams/liter) & - & & $-0.59^{*}$ & 0.03 & $-10.58^{*}$ & 0.14 \\
\hline Maternal age (years) & - & & $-0.92^{*}$ & 0.06 & - & \\
\hline Paternal cognitive score & - & & $-0.22^{*}$ & 0.04 & - & \\
\hline Maternal cognitive score & - & & $-0.84^{*}$ & 0.04 & - & \\
\hline No latrine & - & & 1.60 & 0.94 & - & \\
\hline Vitamin A intake ( $\mu \mathrm{g} R E)$ & - & & $-0.24^{*}$ & 0.03 & - & \\
\hline Body Mass Index & - & & $-2.67^{*}$ & 0.06 & - & \\
\hline Age-squared (months) & - & & - & & $4.67^{*}$ & 0.08 \\
\hline Total coliforms in water source (colonies/100 ml) & - & & - & & 0.02 & 0.11 \\
\hline Total coliforms in water stored (colonies/100 ml) & - & & - & & $0.39 *$ & 0.12 \\
\hline Lagged dependent variable & 0.05 & 0.04 & 0.08 & 0.08 & $-0.42^{*}$ & 0.07 \\
\hline \multicolumn{7}{|c|}{$\begin{array}{l}\text { Notes: } \\
{ }^{1} \text { Maximum likelihood estimates using data on } 312 \text { children in four periods (source: Bhargava 1994). } \\
{ }^{2} \text { MLE using data on } 102 \text { children in three periods (source: Bhargava 1999). } \\
{ }^{3} \text { MLE using data on } 99 \text { children in three periods (source: Bhargava et al. 2003a). } \\
{ }^{*} \mathrm{P}<0.05 \text {. }\end{array}$} \\
\hline
\end{tabular}


First, starting with the common features of the models for the three countries, children's morbidity declined with age, except in Kenya, where the age variable was not significant. Moreover, the coefficients of the lagged dependent variables were not significantly different from zero for Filipino and Kenyan children. In contrast, the estimated coefficient was negative and significant for Bangladeshi children. Although seasonal factors are important for child morbidity, the negative coefficient indicates that children are likely to acquire immunity to infections with time.

Second, children with better nutritional status as reflected in height, weight and hemoglobin concentration faced lower morbidity in the three countries. The opposite signs of the estimated coefficients of height and weight for Filipino children and a likelihood ratio test indicated that height and weight can be combined as the Body Mass Index (BMI; weight/height-squared). BMI was negatively associated with Kenyan children's morbidity index. In contrast, both coefficients of height and weight were estimated with negative signs for Bangladeshi children, indicating that height and weight should not be combined into the BMI. Alternative models were estimated for Kenyan children using lagged heights and weights to assess the robustness of the results. Additionally, previous morbidity levels were included in the models for heights and weights, although the coefficients were generally small and insignificant.

Third, children's $\beta$-carotene intakes in the Philippines and vitamin A intakes in Kenya were negatively and significantly associated with morbidity levels. This was also true for hemoglobin concentration, which was negatively associated with child morbidity in Kenya and Bangladesh. These findings support the view that children with better micronutrient status exhibit greater resilience to infections. Finally, the large and significant coefficients of maternal and paternal scores on cognitive tests in Kenya underscored parental inputs. The coefficient of maternal scores was four times as large in absolute terms, reflecting the benefits of maternal knowledge. The coefficients of parental years of schooling were insignificant, presumably because few parents had attended school

\section{Evidence from India on the Frequency of Foods Consumed and Hemoglobin Concentrations}

Tables 3 and 4 present some new results for Indian children and women's hemoglobin concentration, respectively, using data from the National Family Health Survey-3, which covered more than 40,000 women and 23,000 children. The consumption of 23 foods by children in the previous 24 hours was coded as $0-1$ variables (Bhargava, Guntupalli, and Lokshin 2011). The foods were juice, tea or coffee, fresh or tinned milk, baby formula, baby cereals, porridge or gruel, chicken, meat, foods made from lentils, nuts, bread or noodles, potatoes or tubers, eggs, pumpkin or squash, dark green leafy vegetables, mangoes or papayas, other fruits and vegetables, liver, fresh or 
dried fish, foods made from nuts, cheese or milk products, oil or fat products, and other semi-solid foods. Children's food consumption index ranged from 0-23. In addition, mothers were asked how frequently they consumed seven food groups (milk or curd, pulses or beans, dark green leafy vegetables, fruits, eggs, fish, and meat): daily, once a week, once a month, or never. The maternal food consumption index ranged from 0-210. Because large sample sizes are often necessary to analyze the effects of foods consumed and their frequency on hemoglobin concentration, the results in tables 3 and 4 are presented for all women and children, with the data disaggregated for the states of Kerala and Uttar Pradesh. Kerala is a small state with very high literacy levels, whereas Uttar Pradesh is the largest Indian state with poor access to healthcare.

The empirical model for children's hemoglobin concentration included several variables, such as household composition, index of household possessions, maternal education, access to healthcare and utilization, and treatment against intestinal

Table 3. Estimated Model Parameters for Indian Children's Hemoglobin Concentration from Pooled National Family Health Survey-3 Data and for Kerala and Uttar Pradesh to Investigate the Effects of Children's Consumption of 23 Foods in the past 24 Hours ${ }^{1}$

\begin{tabular}{|c|c|c|c|c|c|c|}
\hline \multirow[b]{2}{*}{ Explanatory variables: } & \multicolumn{2}{|l|}{ All states } & \multicolumn{2}{|l|}{ Kerala } & \multicolumn{2}{|c|}{ Uttar Pradesh } \\
\hline & Coefficient & SE & Coefficient & SE & Coefficient & SE \\
\hline Constant & 65.954 & 0.951 & 70.252 & 7.130 & 73.457 & 2.757 \\
\hline Dummy variable for girl & $0.920^{*}$ & 0.187 & 1.154 & 1.194 & 0.416 & 0.535 \\
\hline Child's age & $0.250^{*}$ & 0.007 & $0.327^{*}$ & 0.045 & $0.271^{*}$ & 0.019 \\
\hline Maternal education & $0.282^{*}$ & 0.027 & $0.474^{*}$ & 0.219 & $0.280^{*}$ & 0.076 \\
\hline Number of older brothers & $-0.243^{*}$ & 0.111 & -0.616 & 0.982 & $-0.851^{*}$ & 0.267 \\
\hline Number of older sisters & -0.043 & 0.096 & 1.323 & 0.971 & 0.425 & 0.246 \\
\hline Household possessions index & $0.366^{*}$ & 0.092 & -0.304 & 0.739 & 0.229 & 0.277 \\
\hline (Household possessions index)-squared & $-0.018^{*}$ & 0.006 & 0.023 & 0.046 & -0.019 & 0.019 \\
\hline Child's DPT vaccinations & $0.261^{*}$ & 0.083 & 1.013 & 0.867 & -0.048 & 0.222 \\
\hline Child's food consumption index ${ }^{2}$ & $0.130^{*}$ & 0.031 & 0.074 & 0.157 & -0.032 & 0.111 \\
\hline Child received drugs for intestinal parasites & $1.527^{*}$ & 0.283 & 1.016 & 1.266 & $-3.005^{*}$ & 1.014 \\
\hline Not utilizing government facilities index & $-1.065^{*}$ & 0.101 & 0.211 & 0.683 & $-0.785^{*}$ & 0.344 \\
\hline Preceding birth interval & $0.015^{*}$ & 0.005 & 0.009 & 0.025 & $0.033^{*}$ & 0.014 \\
\hline No. children at first use of contraceptives & 0.008 & 0.057 & -0.576 & 0.388 & 0.017 & 0.163 \\
\hline Maternal Body Mass Index & $0.246^{*}$ & 0.031 & 0.257 & 0.170 & 0.072 & 0.087 \\
\hline Maternal hemoglobin concentration & $0.174^{*}$ & 0.006 & $0.117^{*}$ & 0.045 & $0.127^{*}$ & 0.016 \\
\hline $\mathrm{R}^{2}$ & $0.130^{*}$ & & $0.154^{*}$ & & $0.094^{*}$ & \\
\hline $\begin{array}{l}\text { Notes: } \\
{ }^{1} \text { There were } 23,437 \text { children in all Indian } \\
\text { Kerala, and 3,013 children in Uttar Pradesh in } \\
{ }^{2} \text { Food consumption index was based on } 23 \\
{ }^{*} \mathrm{P}<0.05 .\end{array}$ & ds consume & jer & evious & rs. & (1) & \\
\hline
\end{tabular}


Table 4. Estimated Parameters from Models for Indian Women's Hemoglobin Concentration using Pooled National Family Health Survey-3 Data and for Kerala and Uttar Pradesh to Investigate the Effects of Women's Consumption of Seven Food Groups in the past Month ${ }^{1}$

\begin{tabular}{|c|c|c|c|c|c|c|}
\hline \multirow[b]{2}{*}{ Explanatory variables: } & \multicolumn{2}{|l|}{ All states } & \multicolumn{2}{|l|}{ Kerala } & \multicolumn{2}{|c|}{ Uttar Pradesh } \\
\hline & Coefficient & SE & Coefficient & SE & Coefficient & SE \\
\hline Constant & 100.438 & 1.728 & 105.738 & 14.086 & 103.034 & 5.052 \\
\hline Maternal age & $0.869^{*}$ & 0.120 & 1.036 & 0.994 & $0.900^{*}$ & 0.344 \\
\hline (Maternal age)-squared & $-0.011^{*}$ & 0.002 & -0.014 & 0.017 & $-0.012^{*}$ & 0.006 \\
\hline Maternal education & $0.177^{*}$ & 0.023 & $0.543^{*}$ & 0.178 & 0.113 & 0.066 \\
\hline Number of children ever born & $-0.400^{*}$ & 0.065 & $-2.375^{*}$ & 0.583 & $-0.360^{*}$ & 0.178 \\
\hline Currently pregnant & $-9.335^{*}$ & 0.294 & $-10.749^{*}$ & 2.258 & $-9.730^{*}$ & 0.778 \\
\hline Difficulties in getting medical help index & $-0.046^{*}$ & 0.020 & 0.001 & 0.176 & 0.061 & 0.064 \\
\hline Household possessions index & $0.386^{*}$ & 0.079 & -0.005 & 0.571 & -0.441 & 0.239 \\
\hline (Household possessions index)-squared & -0.008 & 0.005 & 0.002 & 0.035 & 0.029 & 0.017 \\
\hline Maternal food consumption index ${ }^{2}$ & $0.007^{*}$ & 0.003 & 0.007 & 0.013 & 0.013 & 0.009 \\
\hline Received drugs for intestinal parasites & $1.352^{*}$ & 0.495 & -0.681 & 1.711 & 3.530 & 1.944 \\
\hline Not utilizing government facilities index & $-0.494^{*}$ & 0.088 & -0.978 & 0.541 & -0.128 & 0.294 \\
\hline Preceding birth interval & $-0.017^{*}$ & 0.004 & -0.009 & 0.019 & -0.014 & 0.013 \\
\hline No. children at first use of contraceptives & $-0.377^{*}$ & 0.050 & -0.294 & 0.308 & $-0.457^{*}$ & 0.145 \\
\hline $\mathrm{R}^{2}$ & $0.057^{*}$ & & $0.075^{*}$ & & $0.039^{*}$ & \\
\hline \multicolumn{7}{|c|}{$\begin{array}{l}\text { Notes: } \\
{ }^{1} \text { There were } 42,365 \text { women in all Indian states, } 845 \text { women in Kerala, and } 5.699 \text { women in Uttar Pradesh } \\
\text { samples. } \\
{ }^{2} \text { Food consumption index was based on consumption of seven food groups and their frequencies over the } \\
\text { previous } 30 \text { days. } \\
{ }^{*} \mathrm{P}<0.05 \text {. }\end{array}$} \\
\hline
\end{tabular}

parasites. The primary objective of these results was to assess the effects of children's food consumption patterns on their hemoglobin concentration. In table 3 , the children's food consumption index was estimated with a positive and significant coefficient of 0.13 when the data on all children were pooled and the models were estimated using Ordinary Least Squares. Thus, children who consumed greater numbers of the 23 foods had significantly higher hemoglobin concentrations. However, when the models were estimated separately for 480 children in Kerala and 3013 children in Uttar Pradesh, this coefficient was no longer statistically significant. These findings are presumably due to the nature of data from food frequency questionnaires. In any case, the results showed that the coefficients of variables such as children's DPT vaccinations, drugs received against intestinal parasites, utilization of government health facilities, and maternal education and hemoglobin concentration were significant predictors of children's hemoglobin concentration. Some of the variables remained significant in the models estimated for Kerala and Uttar Pradesh. 
Finally, the maternal food consumption index was a positive and significant predictor of hemoglobin concentration for the pooled sample in table 4 . However, this variable was no longer significant when the models were estimated for Kerala and Uttar Pradesh. Because the frequency of seven food groups consumed was incorporated in the index, this variable might have been expected to perform better than the children's index based on questions about foods consumed over the previous 24 hours. Nevertheless, the lack of statistical significance is not surprising because the seven food groups were broad categories and there was no information about portion sizes. In contrast, 24-hour recall data analyzed for India, the Philippines and Kenya recorded the intakes of approximately 200 foods along with portion sizes. The results in table 4 also indicate that high fertility levels and pregnancy status were associated with lower hemoglobin concentration.

\section{Diet Quality, School Infrastructure, and Children's Cognitive Development}

Economic development depends on the availability of a skilled labor force that is necessary for the production of goods and services (e.g., Schultz 1961; Bhargava et al. 2001). Developing countries, where a majority of children are undernourished and lack school education, are unlikely to be competitive in the age of globalization. Moreover, goods and services demanded by developed countries typically entail high value-added. Although the productivity of unskilled labor can be enhanced by improving their nutritional status, it is not feasible to train illiterate workers for tasks requiring scientific skills; learning is a cumulative process, and skill acquisition requires training. From a food policy viewpoint, it is important that children's cognitive development is not compromised by nutrient deficiencies in their diets.

Further, factors that affect children's physical growth and cognitive development in developing countries are interrelated. For example, higher intakes of protein and iron facilitate not only linear growth but also growth in brain mass (Dobbings and Sands 1978). However, cognitive development is complex and depends on the home environment and school infrastructure, which are often inadequate. To understand the effects of diet quality on child development, it would be helpful to outline certain methodological aspects and present evidence on these issues.

First, there has been an emphasis in the nutrition literature on children's iron intake for cognitive development (e.g., Lozoff 1988; Pollitt 1993). The food policies outlined above to facilitate iron absorption and improve diet quality are likely to have beneficial effects for cognitive development. There may be critical periods during childhood, when micronutrient deficiencies may be highly detrimental and 
specific interventions are necessary. However, evidence on these issues may be difficult to interpret, partly because of the "plasticity" or flexibility of the human brain (Purves 1989) and because the assessment of cognitive development is complex. For example, it is difficult to relate newborn infants' performance on the Brazelton (1984) scale to indicators of under-nutrition (Bhargava 2008). For pre-school children, performance on psychological tests such as Bayley's (1969) developmental scales can be difficult to model due to high within-child variation. Thus, the effects of diet quality on measures of cognitive development are likely to be apparent for school-aged and older children.

The second set of issues is the selection of measures of cognitive development for children and the quantification of the effects of diet quality, anthropometric measures, socioeconomic factors, and school infrastructure on the scores. For example, it is common in psychological research to give a battery of tests to children to assess their cognitive development (e.g., Neumann, Bwibo, and Sigman 1992; Pollitt et al. 1993). This approach is useful in part because the reliability of tests can be poor and because aggregate test scores are better indicators of child development. Moreover, children's scores on school examinations can be compiled from school registers. Although school examination scores are good indicators of learning in developed countries (Goldstein and Thomas 1996), this may not be the case in developing countries, where the educational infrastructure is poor and teachers may assign grades based on participation rather than learning.

Tests developed in education and psychological research and administered by external enumerators can provide a useful assessment of children's learning in developing countries. It is important to focus on "higher order mental functions" (Binet and Simon 1916) because verbal skills are a prerequisite for learning (Vygotsky 1987). Psychologists administer tests such as the "digit span", in which the child repeats numbers in forward and backward orders. Items from Raven's Progressive Matrices (Raven 1965) entail identifying the correct box and are neutral with respect to language. In addition, tests in spelling, reading and arithmetic, referred to as "educational achievement tests", are useful because they are closer to material taught in the classroom. It would be useful to summarize some evidence on Kenyan and Tanzanian school children's test scores.

\section{Child Health, School Infrastructure, and Cognitive Development in Kenya and Tanzania}

The proximate determinants of Kenyan and Tanzanian school children's scores on cognitive and educational achievement tests are presented in table 5. The Kenyan data were from three survey rounds in the Embu region (Neumann, Bwibo, and Sigman 1992; Bhargava 1998). Tanzanian children were enrolled in 10 schools in the control group of a randomized controlled trial in 1997-8 investigating the 
Table 5. Results from Estimating Random Effects Models for Kenyan and Tanzanian Children's Scores on Cognitive and Educational Achievement Tests Explained by Household, Anthropometric, Intake, and Morbidity Variables

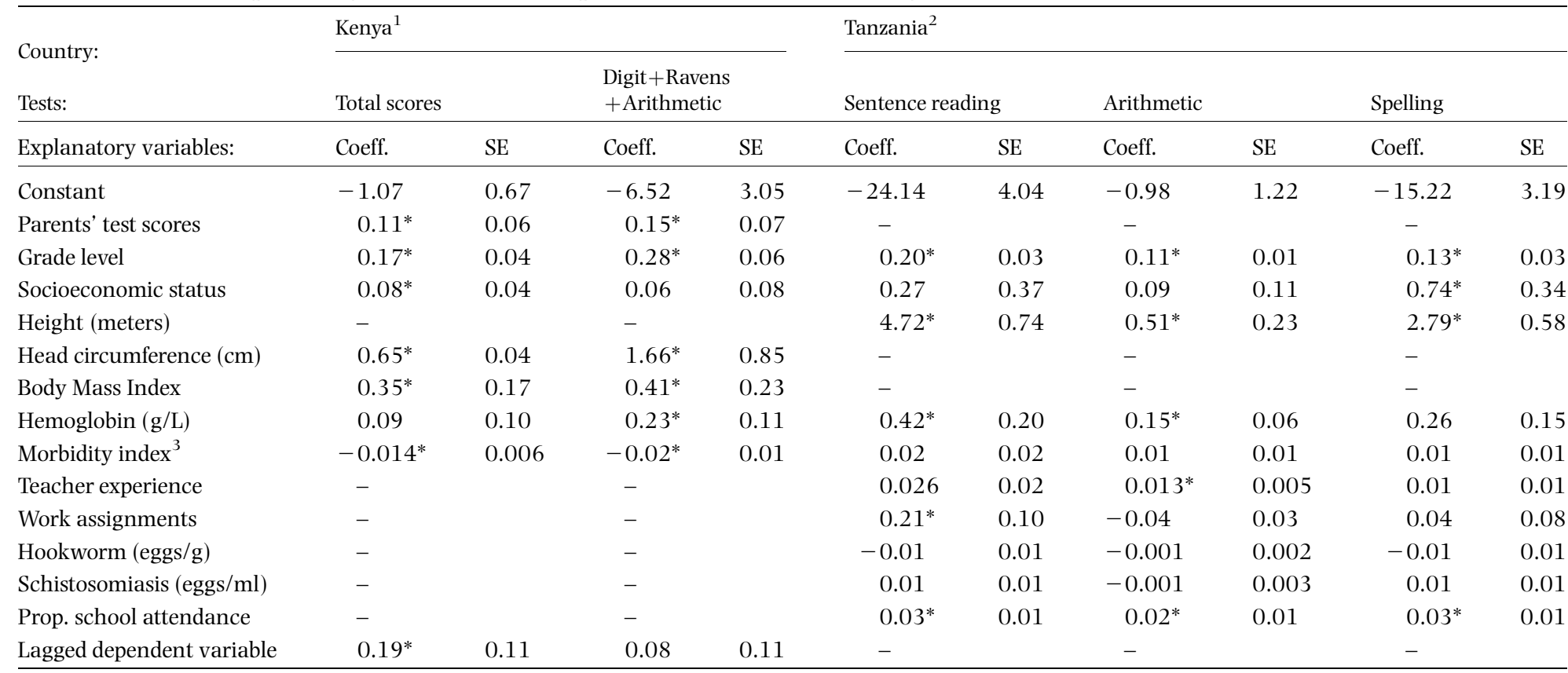

Notes:

${ }^{1}$ Maximum likelihood estimates using data on 104 children in three periods (source: Bhargava 1998).

${ }^{2}$ Efficient estimates from static random effects models using data on 507 children in two periods (source: Bhargava et al. 2005).

${ }^{3}$ Morbidity index was replaced by the C-reactive protein levels in the model for Tanzanian children.

$* \mathrm{P}<0.05$ 
effects of de-worming. Educational achievement tests were given in two survey rounds (Bhargava et al. 2005). The models included explanatory variables such as children's nutritional status, morbidity, grade levels, school infrastructure, and socioeconomic variables.

The main findings in table 5 for Kenya are that children's BMI and head circumference were positively and significantly associated with total scores, whereas morbidity was negatively associated. Although hemoglobin concentration was not a significant predictor of overall test scores, it was significant in the model for scores on digit span, Raven's matrices, and arithmetic. These results indicate the importance of children's diet quality and iron status for test scores reflecting higher order mental functions. Second, in the model for scores on digit span, Raven's matrices, and arithmetic, the coefficient of head circumference was significant. Children's BMI was also significant, whereas morbidity was significantly negatively associated.

For Tanzanian school children, hemoglobin concentration and height were significant predictors of scores on sentence reading, arithmetic, and spelling. An emphasis in the Tanzanian study was on school infrastructure, which can be approximated to some degree using information on textbooks, number of chairs, class size, years of teacher experience, and number of homework assignments. The numbers of work assignments and years of teacher experience were significant predictors of scores on sentence reading and arithmetic, respectively. Moreover, children's school attendance was positively and significantly associated with test scores.

\section{Food Policies, Supply of Nutritious Foods, and Diet Quality in Developing Countries}

Sustainable improvements in diet quality in developing countries entail the availability of nutritious foods at affordable prices especially for the poor. Although the income elasticities of nutrients noted above indicated higher intakes of micronutrients with rises in incomes, from a general equilibrium standpoint, the prices of nutritious foods such as animal products are likely to increase with economic development due to higher demand. To ensure adequate micronutrient intakes by the poor, it is important to increase the supply of nutritious foods, which may require educational campaigns and additional earmarked revenues (Buchanan 1963).

\section{Livestock Production and Diet Quality}

The importance of animal products such as milk and meat for diet quality and nutritional status is widely recognized (e.g., Food and Agriculture Organization 2010; de Beer 2012). Such foods are good sources of protein, calcium, and heme iron, and 
they are important for children's physical development. There are differences in the patterns of demand for milk and meat products in developing countries. In countries such as India, milk products are consumed by many households, whereas meat products are popular in East Asian, sub-Saharan, and Latin American countries. In the absence of refrigeration and other technologies, milk is easily contaminated, which is also true for meat products. Because livestock production plays an essential role in improving population health, it will be useful to discuss strategies for improving the availability and safety of animal products.

First, productivity in the dairy sector is often low in developing countries due to the small numbers of animals that poor households can afford. Cooperatives can facilitate advanced technology for milk processing and obtain higher prices for producers without raising the prices consumers pay (e.g., Alderman 1986). In addition, recent developments such as access to mobile phones can shorten the time that milk is kept without refrigeration via faster communication between small buyers and sellers using text messages. However, it may be difficult to implement computer algorithms requiring "smart phone" technology (Gichamba and Lukandu 2012) without significantly increasing computer literacy among uneducated farmers in developing countries.

Second, fermentation technologies using starter cultures (Holzapfel 2002) can facilitate the preservation of milk products. This is important because contaminated milk products are unhelpful from the standpoint of nutrient absorption and can increase nutrient loss via bacterial infections. Moreover, different types of cheese and meat products with longer shelf lives can be produced using lactic acid bacteria (Leroy and de Vuyst 2004). Finally, increasing fish output from ponds in Bangladesh has been found to increase children's protein, calcium and iron intake (Bouis et al. 1998). Such interventions circumvent some of the storage aspects.

\section{Educational and Media Campaigns for Improving Diet Quality}

Improvements in diet quality in developing countries can be facilitated via different policies for the poor and affluent population subgroups. For example, although reductions in under-nutrition in Thailand have been impressive, there has been slow progress in obesity reduction among the affluent (Chavasit, Kasemsup, and Tontisirin 2013). Because the poor are likely to be less educated, educational and media campaigns to improve maternal and child health outcomes can be implemented via public programs. The Integrated Child Development Services programs in India, for example, encourage locally manufactured, fortified foods for young children to provide dietary energy and essential nutrients (Avula et al. 2011). In contrast, the diets and lifestyles of affluent populations in developing countries might be influenced by educational campaigns such as those designed for reductions in salt and fat intakes in developed countries (Prentice et al. 2006). For 
example, a six-month health education program in Ghana significantly reduced the salt intake and blood pressure of the participants (Cappuccio et al. 2006).

The implementation and evaluation of the effects of educational campaigns, such as campaigns to reduce coronary heart disease in South Africa (Steyn et al. 1997), can be intricate. Although the "low-intensity" mass media campaign, which involved fewer resources, and "high-intensity" interventions over a four-year period produced similar reductions in individuals' risk factors such as blood pressure and low-density lipoprotein ("bad") cholesterol, the follow-up after 12 years showed that communities that received the high-intensity interventions fared poorly compared to those that received the low-intensity campaigns. The greater impact of low-intensity campaign was attributed to "very active" physicians assigned to the communities. Moreover, other health initiatives were undertaken in the communities during the 12-year period. It is often difficult to relate long-term outcomes to initial interventions, especially in population settings that cover large and diverse communities.

The 1987 government campaign in Mauritius to change from palm cooking oil that is high in saturated fat to the healthy soya bean oil lowered individuals' serum cholesterol levels by approximately 15 percent (Uusitalo et al. 1996). Although such campaigns can improve population health, they may be difficult to implement in developing countries, where the population is accustomed to consuming certain ingredients. Media campaigns, such as those for lowering coronary heart disease in subSaharan Africa (Sampson, Amuyunzu-Nyamongo, and Mensah 2013), have helped consumers make healthier food and lifestyle choices. However, due to the ubiquitous availability of processed foods (Monteiro et al. 2013) in developing countries, indirect taxes discouraging consumption may also be useful and are discussed next.

\section{Indirect Taxes on Unhealthy Processed Foods to Improve Population Health}

The coexistence of under-nutrition among the poor and over-weight among affluent populations in developing countries complicates the task of food policy formulation. It is important to reduce fat, sugar, and salt intakes by overweight individuals and to promote physical activity to reduce the risks of chronic diseases. Furthermore, the treatment of chronic diseases is lucrative for medical professionals, whereas infectious diseases associated with poverty are treated with minimal resources (Bhargava 2001). The quality of healthcare that is available to well-off individuals in developing countries is often much higher than the quality of healthcare available to others (Das, Hammer, and Leonard 2008). Thus, the prevalence of obesity in developing countries entails a repugnant redistribution of medical resources from the poor to the affluent, amounting to a negative externality that could be addressed via indirect taxes (Pigou 1932) and other interventions. 
First, there has been an emphasis in developed countries on discouraging the consumption of processed, unhealthy foods containing "added sugars", such as in desserts and soft drinks (Institute of Medicine 2005; Mytton, Clarke, and Rayner 2012). Recent evidence from China suggests that the consumption of processed snacks is increasing, especially among children from affluent households (Wang et al. 2012). Moreover, added sugars have been found to displace the intake of vital nutrients, such as protein, iron, and vitamins A, B, and C among low-income populations in the United States (Bhargava and Amialchuk 2007). Thus, soft drinks and desserts are good candidates for higher indirect taxes to reduce their consumption. In contrast with developed countries, such foods are consumed mainly by the affluent in developing countries, so taxes will be progressive.

Second, there is a paucity of evidence on the magnitudes of price elasticities of demand for unhealthy foods, even from developed countries. Researchers often invoke unrealistic assumptions, such as "price elasticities for food items do not vary across income quintiles" (Nnoaham et al. 2009). Despite the limited information, higher taxes on foods containing added sugars and fats are likely to be beneficial for population health. If, for example, the demand for unhealthy processed foods is elastic and taxes reduce consumption, then higher taxes will help lower the prevalence of diabetes and cardiovascular disease. In contrast, if the demand is inelastic, then greater revenues can be raised due to small reductions in consumption.

Third, the sugar, fat, and salt contents of processed foods can be considered in the design of indirect taxes. Moreover, the labeling of processed foods in developing countries will benefit from labeling systems in developed countries (e.g., Young and Swinburn 2002). For example, even among low-income households in the United States, reading nutrition labels was positively associated with the ratios of carbohydrate, $\beta$-carotene, and fiber intakes to energy intake and was negatively associated with fat intake (Bhargava 2004).

Fourth, countries such as Australia, Canada, Denmark, and Mexico are experimenting with differential taxes depending on the nutrient composition of foods. Although the "fat" tax on saturated fats imposed in Denmark in October 2011 was abruptly rescinded in November 2012 (partly due to opposition from food manufacturers and retailers), there were redistributive issues regarding the burden of the tax on the poor and price increases of butter by discount stores (Jensen and Smed 2013). The long-term effects of this tax on population health outcomes will be difficult to assess. In contrast, the effects of the tax enacted in Mexico in 2010 on the consumption of sugar-sweetened beverages (Barquera, Campos, and Rivera 2013) will provide useful information for developing countries considering tax schemes.

Fifth, earmarked revenues can help achieve policy goals in certain situations (McCleary 1991; Jimenez and Paqueo 1996). This is particularly true in cases where it may be difficult to raise additional revenues without specifying redistribution objectives and individuals' willingness-to-pay may be difficult to ascertain. 
Finally, public and private health insurance programs should encourage greater utilization of preventive services to reduce the consumption of processed unhealthy foods and to reduce chronic diseases through greater physical activity. Although such strategies have been investigated in randomized controlled trials in developed countries, it is important to integrate nutrition counseling and physical exercise in healthcare services in developing countries.

\section{Conclusion}

This paper considered several factors that affect diet quality in developing countries and the effects of nutrient absorption on child health from the viewpoint of food policy formulation. Moreover, factors underlying the supply of nutritious foods were examined. In this section, we summarize the main findings. First, the estimated income elasticities of energy and nutrient intakes using data from India, the Philippines, and Kenya underscored the roles of household incomes for improving diet quality. For micronutrients such as iron, absorption rates are low, so it is important to focus on bioavailable iron intakes to reduce deficiencies. For example, it would be helpful to design policies to improve the iron content of staple foods such as rice and beans while increasing the intakes of vegetables such as orange flesh sweet potato that contain higher quantities of $\beta$-carotene. Such policies will gradually benefit large numbers of individuals, although the evaluation of the benefits would require an extended time frame.

Second, the magnitudes of income elasticities of calcium intakes showed increases with household incomes in India, the Philippines, and Kenya. Dairy products are good sources of calcium and increase the intake of heme iron that is readily absorbed. Thus, the promotion of dairy farming is likely to have beneficial effects for child health. Such interventions have been successful in increasing children's physical growth in developed countries so that less emphasis needs to be placed on shortterm evaluations in developing countries.

Third, the effects of environmental factors such as poor sanitation and water quality on children's morbidity were emphasized because they hinder nutrient absorption. The evidence on Filipino, Kenyan, and Bangladeshi children showed the importance of good nutritional status assessed via intake of vitamin A and height, weight and hemoglobin concentration to reduce morbidity. The results for Indian children's hemoglobin concentration indicated the importance of the utilization of healthcare services.

Fourth, for pre-school and school-aged children, food and health policies should improve the nutritional status of younger children, especially when resources are limited. Morbidity levels typically decline with age as immunity systems develop. Previous analyses of Filipino and Kenyan data also showed beneficial effects of diet 
quality for children's age-adjusted height and weight (Bhargava 1994, 1999). Thus, food policies such as maternal supplementation programs during pregnancy to improve birth outcomes, supplementation of lactating mothers to support infant growth, and supplementation programs for preschool children are likely to improve children's growth. In addition, family planning programs that enable birth spacing reduce demands on the low maternal nutrient stores in developing countries.

Fifth, encouraging livestock production will be helpful for child growth because dairy products increase calcium and heme iron intakes. In addition, the cultivation of fruits and vegetables, even on a small scale, can increase vitamin A and C intakes, which enhance non-heme iron absorption. Although the resources available for dairy farming and vegetable cultivation are often limited, additional revenues from taxing unhealthy processed foods can support higher intakes of animal products by the poor. Sixth, children's cognitive development is critical for the future supply of skilled labor and for economic development. Improving diet quality in terms of protein and micronutrient intakes will be beneficial for children's physical and cognitive development. Future gains in economic productivity from education are likely to be substantial, as demonstrated by impressive economic growth in countries such as Japan, South Korea, and China.

Finally, it is important to design educational programs and indirect taxes on unhealthy processed foods to improve diet quality. A lower burden of chronic disease will, in turn, enable greater healthcare resources for the poor. More elaborate food labeling systems, educational campaigns, and taxes on processed foods that depend on fat, sugar, and salt content can improve population health and economic productivity in developing countries.

\section{Note}

Alok Bhargava is currently at the University of Maryland School of Public Policy, College Park, MD 20742; Bhargava@umd.edu. This study was partially supported by the Harvest Plus program of the International Food Policy Research Policy Institute. While retaining responsibility for the views expressed in this study, the author thanks E. Birol, H. Bouis, and E. Jimenez for useful discussions. Revisions of this paper have benefitted from several helpful comments from three reviewers and the editor. I would like to dedicate this paper to the loving memory of my mother, Shakuntala Bhargava, from whom I learned the importance of diet quality for child development.

\section{References}

Alderman, H. 1986. "Cooperative dairy development in Karnataka, India: An assessment." Research Report \#64. International Food Policy Research Institute, Washington, DC.

Alderman, H., and D. Bundy. 2012. "School feeding programs and development: Are we framing the questions correctly?” World Bank Research Observer 27 (2) : 204-21. 
Arimond, M., and M. Ruel. 2004. "Dietary diversity is associated with child nutritional status: Evidence from 11 Demographic and Health Surveys." Journal of Nutrition 134 (10) : 2579-85.

Arrow, K., P. Dasgupta, L. Goulder, K. Mumford, and K. Oleson. 2012. "Sustainability and the measurement of wealth." Environment and Development Economics 17 (3) : 317-53.

Avula, R., E. Frongillo, M. Arabi, S. Sharma, and W. Schultink. 2011. "Enhancements to nutrition program in Indian integrated child development services increased growth and energy intake of children." Journal of Nutrition 141 (4) : 680-4.

Barquera, S., I. Campos, and J. Rivera. 2013. "Mexico attempts to tackle obesity: The process, results, push back and challenges." Obesity Reviews 14 (Supp. 2) : 69-78.

Bauernfeind, J. 1994. "Nutrification of foods.” In M. Shils, J. Olson, and M. Shike, eds., Modern nutrition in health and disease. Philadelphia: Lea and Febiger.

Bayley, N. 1969. Bayley scales of infant development. New York: Psychological Corporation.

Behrman, J., and A. Deolalikar. 1987. "Will developing country nutrition improve with incomes? A case study for rural south India." Journal of Political Economy 95 (3) : 492-507.

Behrman, J., M. Calderon, S. Preston, J. Hoddinot, R. Martorell, and A. Stein. 2009. "Nutritional supplementation in girls influences the growth of their children: Prospective study in Guatemala." American Journal of Clinical Nutrition 90 (5) : 1372-9.

Bhandari, N., R. Bahl, B. Nayyar, P. Khokhar, J. Rohde, and M. Bhan. 2001. "Food supplementation with encouragement to feed it to infants from 4 to 12 months of age has a small impact on weight gain." Journal of Nutrition 131 (7) : 1946-51.

Bhargava, A. 1991a. "Estimating short and long run income elasticities of foods and nutrients for rural south India." Journal of the Royal Statistical Society A 154 : 157-74.

1991b. "Identification and panel data models with endogenous regressors." Review of Economic Studies 58 : $129-40$.

. 1994. "Modelling the health of Filipino children." Journal of the Royal Statistical Society, Series A $157: 417-32$.

1998. "A dynamic model for the cognitive development of Kenyan schoolchildren." Journal of Educational Psychology 90 (1) : 162-7.

1999. "Modelling the effects of nutritional and socioeconomic factors on the physical development and morbidity of Kenyan school children." American Journal of Human Biology 11 (3) : $317-26$.

2001. “World Health Report 2000." Lancet 358 (9287) : 1097-8.

2004. "Socio-economic and behavioural factors are predictors of food use in the National Food Stamp Program Survey.” British Journal of Nutrition 92 (3) : 497-506.

2008. Food, economics, and health. Oxford: Oxford University Press.

Bhargava, A., and A. Amialchuk. 2007. "Added sugars displaced the use of vital nutrients in the National Food Stamp Program Survey." Journal of Nutrition 137 (2) : 453-60.

Bhargava, A., H. E. Bouis, and N. S. Scrimshaw. 2001. "Dietary intakes and socioeconomic factors are associated with the hemoglobin concentration of Bangladeshi women." Journal of Nutrition 131 (3) : 758-64.

Bhargava, A., H. E. Bouis, K. Hallman, and B. A. Hoque. 2003a. "Coliforms in the water and hemoglobin concentration are predictors of gastrointestinal morbidity of Bangladeshi children ages 1-10 years." American Journal of Human Biology 15 (2) : 209-19.

Bhargava, A., and M. Fox-Kean. 2003. "The effects of maternal education versus cognitive test scores on child nutrition in Kenya." Economics \& Human Biology 1 (3) : 309-19. 
Bhargava, A., A. Guntupalli, and M. Lokshin. 2011. "Healthcare utilization, socioeconomic factors and child health in India." Journal of Biosocial Science 43 (6) : 701-15.

Bhargava, A., A. Guntupalli, M. Lokshin, and L. Howard. 2014. "Modeling the effects of immunizations timing on child health outcomes in India." Health Economics 23 (5) : 606-20.

Bhargava, A., D. T. Jamison, L. J. Lau, and C. J. Murray. 2001. "Modeling the effects of health on economic growth." Journal of Health Economics 20 (3) : 423-40.

Bhargava, A., M. Jukes, J. Lambo, C. M. Kihamia, W. Lorri, C. Nokes, L. Drake, and D. Bundy. 2003 b. "Anthelmintic treatment improves the hemoglobin and serum ferritin concentrations of Tanzanian schoolchildren." Food \& Nutrition Bulletin 24 (4) : 332-42.

Bhargava, A., M. Jukes, D. Ngorosho, C. Khilma, and D. Bundy. 2005. "Modeling the effects of health status and the educational infrastructure on the cognitive development of Tanzania school children." American Journal of Human Biology 17 (3) : 280-92.

Bhutta, Z., J. Das, A. Zizvi, M. Gaeffey, N. Walker, S. Horton, P. Webb, A. Lartey, and R. Black. 2013. "Evidence-based interventions for improvement of maternal and child nutrition: what can be done and at what cost?" Lancet 382 (9890) : 452-77.

Binet, A., and T. Simon. 1916. The development of intelligence in children. Baltimore: Williams and Wilkins.

Binswanger, H., and N. Jodha. 1978. Manual for Instruction for Economic Investigators in ICRISAT's Village Level Studies. Hyderabad: International Crops Research Institute for Semi-arid Tropics.

Block, G., A. Hartman, C. Dresser, M. Carrollo, J. Gannon, and L. Gardner. 1986. "A data-based approach to diet questionnaire design and testing." American Journal of Epidemiology 124 (3) : 453-69.

Bouis, H., and L. Haddad. 1992. "Are estimates of calorie-income elasticities too high?” Journal of Development Economics 39 (2) : 333-64.

Bouis, H. E., B. Briere, L. Guitierrez, K. Hallman, N. Hassan, O. Hels, and W. Quabiliet al. 1998. "Commercial vegetable and polyculture fish production in Bangladesh: Their impacts on income, household resource allocation, and nutrition." Gender and Intrahousehold Aspects of Food Policy Project Brief 2. International Food Policy Research Institute, Washington, DC.

Brazelton, T. 1984. Neonatal Behavioral Assessment Scale, 2nd edition. London: Blackwell.

Buchanan, J. 1963. "The economics of earmarked taxes." Journal of Political Economy 71 (5) : 457-69.

Calloway, D. H., S. P. Murphy, and S. Bunch. 1994. User's guide to the international minilist nutrient data base. Department of Nutritional Sciences, University of California, Berkeley, CA.

Cappuccio, E., S. Kerry, E. Micah, J. Plange-Rhule, and J. Eastwood. 2006. "A community programme to reduce salt intake and blood pressure in Ghana." BMC Public Health 6 : 13.

Carroll, R., L. Freedman, and A. Hartman. 1996. "Use of semiquantitative food frequency questionnaires to estimate the distribution of usual intakes." American Journal of Epidemiology 143 (4) : $392-404$.

Cebu Study Team. 1991. "Underlying and proximate determinants of child health: The Cebu Longitudinal Health and Nutrition Survey." American Journal of Epidemiology 133 (2) : 185-201.

Chavasit, V., V. Kasemsup, and K. Tontisirin. 2013. "Thailand conquered under-nutrition very successfully but has not slowed obesity." Obesity Reviews 14 (Suppl 2) : 96-105.

Checkley, W., L. Epstein, R. Gilman, L. Cabrera, and R. Black. 2003. "Effects of acute diarrhea on linear growth of Peruvian children." American Journal of Epidemiology 157 (2) : 166-75.

de Beer, H. 2012. "Dairy products and physical stature: A systematic review and meta-analysis of controlled trials." Economics and Human Biology 10 (3) : 299-309. 
Das, J., J. Hammer, and K. Leonard. 2008. "The quality of medical advice in low-income countries." Journal of Economic Perspectives 22 (2) : 93-114.

Dobbings, J., and K. Sands. 1978. "Head circumference, biparietal diameter and brain growth in fetal and postnatal life." Early Human Development 2 (1) : 81-7.

Dreze, J., and A. Sen. 1990. Hunger and public action. Oxford: Claredon Press.

Dutch School Milk Programs. 2011. "Nostalgia and bygone times: Do you remember?" Available at: http://kanaalridder.blogspot.sg/2011/11/m-brigadier.html

Ekstrom, E.-C., S. M. Z. Hyder, A. M. Chowdhury, S. A. Chowdhury, B. Lonnerdal, J. P. Habicht, and L. A. Persson. 2002. "Efficacy and trial effectiveness of weekly and daily iron supplementation among pregnant women in rural Bangladesh: Disentangling the issues." American Journal of Clinical Nutrition 76 (6) : 1392-400.

Esrey, S., J. Habicht, M. Latham, D. Sisler, and G. Casella. 1988. "Drinking water source, diarrheal morbidity, and child growth in villages with both traditional and improved water supplies in rural Lesotho, Southern Africa." American Journal of Public Health 78 (11) : 1451-5.

Fogel, R. W. 1994. "Economic growth, population theory and physiology: The bearing of long-term processes on the making of economic policy." American Economic Review 84 (3) : 369-95.

Food and Agriculture Organization. 2010. Livestock sector policies and programmes in developing countries. Rome: Food and Agriculture Organization.

Gichamba, A., and I. Lukandu. 2012. "A model for designing M-agriculture applications for dairy farming." African Journal of Information Systems 4 (4) : 120-36.

Goldstein, H., and S. Thomas. 1996. "Using examination results as indicators of school and college performance." Journal of the Royal Statistical Society A 159 : 149-63.

Gorman, W. M. 1967. "Tastes, habits and choices.” International Economic Review 8 (2) : 218-22.

Haas, J., J. Beard, L. Murray-Kolb, A. del Mundo, A. Felix, and G. Gregorio. 2005. "Iron-biofortified rice improves the iron stores of nonanemic Filipino women." Journal of Nutrition 135 (12) : 2823-30.

Holzapfel, W. 2002. "Appropriate starter culture technology for small-scale fermentation in developing countries." International Journal of Food Microbiology 75 (3) : 197-212.

Hotz, C., C. Loechi, A. Lubowa, J. K. Tumwine, G. Ndeezi, A. Nandutu Masawi, and R. Bainganaet al. 2012. "Introduction of $\beta$-carotene-rich orange sweet potato in rural Uganda resulted in increased vitamin A intakes among children and women and improved vitamin A status among children." Journal of Nutrition 142 (10) : 1871-80.

Humphrey, J. 2009. "Child undernutrition, tropical enteropathy, toilets, and handwashing." Lancet 374 (9694) : 1032-5.

Institute of Medicine. 2005. Dietary reference intakes for energy, carbohydrate, fiber, fat, fatty acids, cholesterol protein and amino acids. Washington: National Academy Press.

Jensen, J., and S. Smed. 2013. "The Danish tax on saturated fat- short run effects on consumption, substitution patterns and consumer prices of fats." Food Policy $42: 18-31$.

Jimenez, E., and V. Paqueo. 1996. "Do local contributions affect efficiency of public primary schools?" Economics of Education Review 15 (4) : 377-86.

Jones, A., S. Ickes, L. Smith, M. Mbuya, B. Chasekwa, R. Heidkamp, P. Menon, A. Zongrone, and R. Stoltzfus. 2014. "World Health Organization infant and young child feeding indicators and their associations with child anthropometry: A synthesis of recent findings." Maternal and Child Nutrition $10(1): 1-17$.

Leroy, F., and L. de Vuyst. 2004. "Lactic acid bacteria as functional starter cultures for the food fermentation industry." Trends in Food Science \& Technology 15 (2) : 67-78. 
Lozoff, B. 1988. "Behavioral alterations in iron deficiency." Advances in Pediatrics 35 : 331-60.

Luby, S., M. Agboatwalla, D. Felkin, J. Painter, W. Billhimer, A. Atlaf, and R. Hoekstra. 2005. "Effects of handwashing on child health: A randomised controlled trial." Lancet 366 (9481) : 225-33.

Mahal, A., and A. Karan. 2008. "Adequacy of dietary intakes and poverty in India: Trends in the 1990s." Economics and Human Biology 6 (1) : 57-74.

Maluccio, J., J. Hoddinott, J. Behrman, R. Martorell, A. Quisumbing, and A. Stein. 2009. "The impact of improving nutrition during early childhood on education among Guatemalan adults." Economic Journal 119 (537) : 734-63.

Martorell, R., and N. Scrimshaw, N., eds. 1995. "The effects of improved nutrition in early childhood: The Institute of Nutrition of Central America and Panama follow-up study." Journal of Nutrition 125 (4 Suppl) : 1027S-138S.

Martorell, R., J. Behrman, R. Grajeda, and J. Hoddinot, eds. 2005. "The human capital 2002-04 study in Guatemala: A follow-up to the INCAP Longitudinal Study 1969-77." Food and Nutrition Bulletin 26 (2) : S1-S124.

McCleary, W. 1991. "The earmarking of government revenue." World Bank Research Observer 6 (1) : $81-104$.

Monckeberg, F. 1975. "Effects of malnutrition on physical growth and brain development." In J. Prescott, M. Reeds, and D. Coursin, eds., Brain function and malnutrition: Neurophysiological method of assessment. New York: John Wiley.

Monteiro, C., J.-C. Moubarac, G. Cannon, S. Ng, and B. Popkin. 2013. "Ultra-processed products are becoming dominant in the global health system." Obesity Reviews 14 (Suppl S2) : 21-28.

Moursi, M., M. Arimond, K. Dewey, S. Treche, M. Ruel, and F. Delpeuch. 2008. "Dietary diversity is a good predictor of the micronutrient density of the diet of 6- to 23-month-old children in Madagascar." Journal of Nutrition 138 (12) : 2448-53.

Mytton, O., D. Clarke, and M. Rayner. 2012. "Taxing unhealthy food and drinks to improve health." British Medical Journal 344 : e2931.

Nestel, P., H. Bouis, J. Meenakshi, and W. Pfeiffer. 2006. "Biofortification of staple crops." Journal of Nutrition 136 (4) : 1064-7.

Neumann, C., N. Bwibo, and M. Sigman. 1992. Functional implications of malnutrition. Kenya project final report. Washington, DC: United States Agency for International Development.

Nnoaham, K., G. Sacks, M. Rayner, O. Mytton, and A. Gray. 2009. "Modelling income group differences in the health and economic impacts of targeted food taxes and subsidies." International Journal of Epidemiology 38 (5) : 1324-33.

Pigou, A. 1932. The economics of welfare. 4th edition. London: MacMillan.

Pinstrup-Andersen, P. 2013. Nutrition-sensitive food systems: from rhetoric to action. The Lancet 382 (9890) : 375-6.

Pitt, M. 1983. "Food preferences and nutrition in rural Bangladesh." Review of Economics and Statistics 65 (1) : 105-14.

Pollitt, E. 1993. "Iron deficiency and cognitive function.” Annual Review of Nutrition 13 : 521-37.

Pollitt, E., K. Gorman, P. Engle, R. Martorell, and J. Rivera. 1993. "Early supplementary feeding and cognition." Monographs of Society for Research in Child Development $58: 7$.

Prentice, R., B. Caan, R. Chlebowski, R. Patterson, L. H. Kuller, J. K. Ockene, K. L. Margolis, and M. C. Limacheret al. 2006. "Low-fat dietary pattern and risk of invasive breast cancer: The Women's Health Initiative Randomized Controlled Dietary Modification Trial." Journal of American Medical Association 295 (6) : 629-42. 
Purves, D. 1989. Body and brain: A trophic theory of neural connections. Cambridge: Harvard University Press.

Rand Corporation. 1983. Measurement of physiologic health for children volumes 1-5. Santa Monica: Rand Corporation.

Raven, J. 1965. The coloured progressive matrix test. London: Lewis.

Ruel, M., and H. Alderman. 2013. Nutrition-sensitive interventions and programmes: How can they help to accelaerate progress in improving maternal and child nutrition? The Lancet 382 (9891) : 536-51.

Sampson, U., M. Amuyunzu-Nyamongo, and G. Mensah. 2013. "Health promotion and cardiovascular disease prevention in sub-Saharan Africa." Progress in Cardiovascular Diseases 56 (3) : 344-55.

Schultz, T. W. 1961. "Investment in Human Capital.” American Economic Review 51 (1) : 1-17.

Schonbeck, Y., H. Talma, P. van Dommelen, B. Bakker, S. Buitendijk, R. HiraSing, and S. van Buuren. 2013. "The world's tallest nation has stopped growing taller: The height of Dutch children from 1955-2009." Pediatric Research 73 (3) : 371-7.

Scrimshaw, N., and J. San Giovanni. 1997. "Synergism of nutrition, infection, and immunity: an overview." American Journal of Clinical Nutrition 66 (2) : 464S-477S.

Sempos, C. 1992. "Some limitations of semiquantitative food frequency questionnaires." American Journal of Epidemiology 135 (10) : 1127-32.

Sommer, A. 1986. Nutritional blindness. New York: Academic Press.

Spears, D. 2013. "The nutritional value of toilets: How much international variation in heights can sanitation explain?” Discussion Paper, Delhi School of Economics, Delhi, India.

Stefanik, P., and M. Trulson. 1962. "Determining the frequency intakes of foods in large group studies." American Journal of Clinical Nutrition 11 : 335-43.

Steyn, K., M. Steyn, A. Swanepoel, P. Jordaan, P. Jooste, J. Fourie, and J. Rossouw. 1997. "Twelve-year results of the Coronary Risk Factor Study (CORIS)." International Journal of Epidemiology 26 (5) : 964-71.

Stigler, G. 1945. “The cost of subsistence.” Journal of Farm Economics 27 : 303-14.

Timmer, C. P., W. Falcon, and S. Pearson. 1983. Food policy analysis. Baltimore: Johns Hopkins University Press.

UNICEF/UNU/WHO/MI. 1999. "Preventing iron deficiency in women and children. Background and consensus on key technical issues and resource for advocacy, planning and implementing national programmes." International Nutrition Foundation, Boston, MA.

Uusitalo, U., E. Feskens, J. Tuomilehto, G. Dowse, U. Haw, D. Fareed, F. Hemraj, H. Gareeboo, K. Alberti, and P. Zimmet. 1996. "Fall in total cholesterol concentration over five years in association with changes in fatty acid composition of cooking oil in Mauritius: Cross sectional survey." British Medical Journal 313 (7064) : 1044-6.

Vygotsky, L. S. 1987. “Thinking and speech.: In R. W. Rieber, and A. S. Carton, eds., Collected works of L.S. Vygotsky Volume 1. New York: Plenum.

Wang, Z., F. Zhai, B. Zhang, and B. Popkin. 2012. "Trends in Chinese snacking behaviors and patterns and the social-demographic role between 1991 and 2009." Asia Pacific Journal of Clinical Nutrition $21(2): 253-62$.

Willett, W. 1998. Nutritional epidemiology. 2nd edition. Oxford: Oxford University Press.

Young, L., and B. Swinburn. 2002. "Impact of the Pick the Tick food information programme on the salt content of food in New Zealand." Health Promotion International 17 (1) : 13-9. 